\title{
2-Year Student/Teacher Pedometer Tracking Program Equals Increased Steps during the School Day
}

\author{
P Brian Kiessling II*, Carol Kennedy Armbruster, Jessica Yoder, Michael Frisby and William Ramos \\ Indiana University, School of Public Health Recreation, USA
}

Submission: April 10, 2018; Published: April 25, 2018

*Corresponding author: P Brian Kiessling II, Indiana University, School of Public Health Recreation, Parks, Tourism Studies, Bloomington, Indiana, USA, Email: pbkiessl@indiana.edu

\begin{abstract}
A teacher-led committee at an urban Midwestern elementary school created a pedometer tracking program with the goal of increasing movement throughout the school day for teachers and students. Due to budgetary concerns, the teacher-led committee strived to create a program which could be easily replicated and implemented at low-costs while still improving movement outcomes for teachers and students. Mutual accountability in obtaining positive movement outcomes was utilized as a framework to benefit the entire school community through a partnership of teachers, students, and administration. The 2-year pedometer program revealed a significant increase in movement during the school day for teachers and students as well as a significant and moderate relationship between step improvement for teachers and students. The program was found to promote movement for children in the classroom as well as teachers in their workplace and could be a cost-effective way to increase movement for both groups during the school day.
\end{abstract}

Keywords: Movement; Pedometers; Classroom; Elementary; Students; Teachers; School

Abbreviations: CDC: Center for Disease Control; MVPA: Moderate To Vigorous Physical Activity; YRBSS: Youth Risk Behavior Surveillance System; PA: Physical Activity; ACSM: American College of Sports Medicine; CSPAP: Comprehensive School Physical Activity Program; GLL: Give Learning Legs; YPAII: Youth Physical Activity Intervention Implementation

\section{Introduction}

In 2015, life expectancy at birth declined to 78.8 years for the total U.S. population, which represented a decrease in overall life expectancy for the first time since 1993 [1]. Parallel to this decline in life expectancy, $31.8 \%$ of children in the United States are either obese or overweight [2]. Additionally, the majority of children in the U.S. do not meet the national guidelines 3 of 60 minutes of moderate to vigorous physical activity (MVPA) per day recommended by the Center for Disease Control (CDC) and the US Department of Health and Human Services $[3,4]$. Finally, research has shown that children who are overweight or obese are likely to be obese as adults [5]. Sedentary behaviors and physical inactivity are most certainly contributing factors to the obesity epidemic which is especially prevalent in the Midwest [6,7]. The Youth Risk Behavior Surveillance System (YRBSS) and the CDC show $14 \%$ of youth are not meeting the 60 minute physical activity (PA) guideline on even one day per week, while $51 \%$ did not meet the 60 minute PA guideline for five days/week [8]. Regular PA decreases the risk for several chronic health problems and can reduce levels of anxiety and depression as well as build and maintain bones and muscles [9]. In addition to physical health benefits, a multitude of studies show academic benefits as a result of increased physical activity [10-14]. A recent study found that when a school focused on enhancing physical activity, the odds were doubled that students would achieve national learning objectives compared to those who did no additional activity [15]. The amount of time children and adolescents spend engaging in excessive amounts of sedentary time have increased in recent years [3]. Sedentary time is positively associated with increased rates of diabetes and insulin resistance and can also impact cognitive learning abilities $[16,17]$. Increased time spent engaging in sedentary behavior is linked with increased mortality risks, but studies have shown that any movement breaking up prolonged sedentary time is beneficial and is associated with better health $[18,19]$ Children spend a large portion of their day at school, and while at school, spend more time in sedentary behavior with fewer recorded breaks compared with non-school time.16 More frequent interruptions to sedentary time during the school day could lead to metabolic and musculoskeletal benefits for students [16]. 


\section{Juniper Online Journal of Public Health}

The US 2018 Physical Activity Guidelines Advisory committee report for the soon to be released 2018 Physical Activity Guidelines stated the following "For individuals who perform no or little moderate-to-vigorous physical activity, replacing sedentary behavior with light-intensity physical activity reduces the risk of all-cause mortality, cardiovascular disease incidence and mortality, and the incidence of type 2 diabetes. Before this report, evidence that light-intensity physical activity could provide health benefits had not been clearly stated [20]." In general, public health has realized the need for increased movement and decreased sedentary behaviors, which has led to professional organizations developing messaging to increase movement among children. Nike, the American College of Sports Medicine (ACSM), and the International Council of Sport Science and Physical Education developed a "designed to move" campaign in 2015, which arose out of concern for increasing rates of childhood obesity and a desire to develop messaging to increase movement among kids [21]. Additionally, in the 2016 National Physical Activity Plan, the CDC calls for schools to increase physical activity throughout the day [22]. Even with such recommendations, many schools are reducing or eliminating physical education programs and recess because of budgetary and time constraints.

The percentage of schools offering physical education daily or at least three days a week declined dramatically from 2001 to 2006 [23]. According to a recent report by the Institute of Medicine of the National Academy, 44 percent of the nation's school administrators have cut significant amounts of time from physical education, arts and recess so that more time could be devoted to reading and mathematics [23]. In an effort to increase levels of physical activity, stability balls, standing desks, pedal desks and various other exercise machines have been added to classrooms and have provided mixed results. Early studies of interventions with standing desks and stability balls have shown reduced time seated and increased time standing. The equipment interventions have not caused behavior or attention problems, but physical activity and step counts were not significantly altered in most studies [19,24-26]. This equipment can carry a prohibitive price tag, and more research is needed to see the effects of equipment interventions on physical activity and sedentary behaviors in the classroom. Regardless of the effectiveness of equipment-based interventions, most schools are unable to devote the resources necessary to implement such interventions, and thus more cost-effective programs must be explored for the greatest public health benefits.

Under the No Child Left Behind legislation funding provided by federal and state governments was predominantly spent on increasing standardized test scores. In response to declining physical education programs and a growing sedentary culture in schools, SHAPE America and the CDC encouraged schools to capitalize on opportunities to be physically active. Within the Comprehensive School Physical Activity Program (CSPAP), schools are encouraged to increase physical activity during the school day [27]. Under this initiative responsibility for increasing movement for students is moved away from the physical education teachers and encouraging low cost, innovative methods. Instead of investing funds in costly exercise equipment for classrooms, a starting point may be to first raise awareness of the importance of physical activity throughout the day and help teachers and students quantify how much they are moving or sitting. Teachers can incorporate physically active lessons as well as short activity breaks throughout the day to positively influence physical activity levels, behavior, attentiveness and academic performance $[10-12,28,29]$. School environments that are redesigned to permit and incorporate physical activity seem to raise activity levels more than traditional environments that simply trade seated desks for standing ones [30]. In addition, standing desks may not combat all the negative effects of sedentary behavior the same way as simple daily movement does [31]. Tudor-Locke et al (2011) found that a direct estimate of minimal amounts of moderate to vigorous physical activity (MVPA) needed to meet the daily MVPA guidelines accumulated in the course of free-living behavior for adults is $7,000-8,000$ steps/day [32]. For adolescents, 10,000 to 11,700 steps may be associated with 60 minutes of MVPA [33]. This estimation allows step counts to be compared with MVPA guidelines, which could be especially beneficial in a school setting. While both adults and children need to move more during the day, there is little research correlating teacher movement and student movement in the classroom. Low-cost interventions focused on movement could be key to increasing movement during the school day for both students and teachers. The wellness committee sought to create a program which could be implemented without the costs associated with many equipment-based movement interventions. The framework for the 2-year student and teacher pedometer tracking program was based on partnerships created by a teacher-driven, administration-supported wellness committee and perhaps most importantly, student involvement. Figure 1 summarizes graphically the vision of how the entire school community (teachers/administrators/students) held each other accountable in this pedometer tracking program based on movement outcomes to support the greater school community.

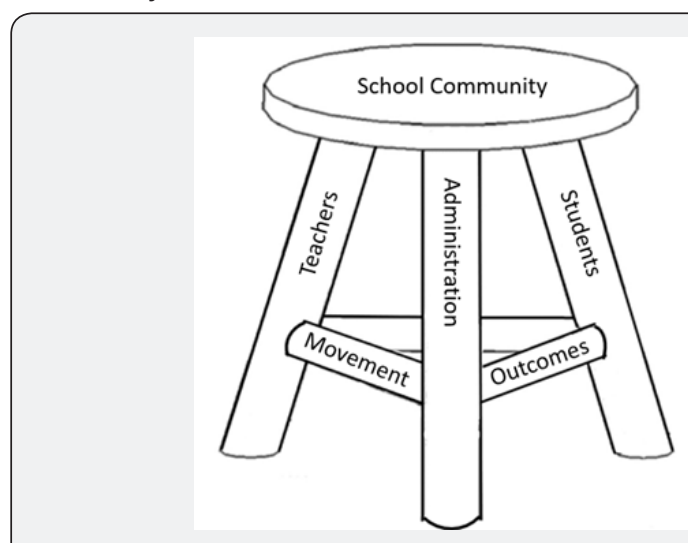

Figure 1 


\section{Juniper Online Journal of Public Health}

\section{Materials and Methods}

\section{Participants}

This study was conducted within an urban, low-income Midwestern elementary school (K-6) in a large metropolitan city where $86.5 \%$ of students receive free lunch. The school also had low passing rates on standardized tests compared to other schools in the same state. $65.3 \%$ of students were Caucasian. Although there was a committed interest within the administration to incorporate more health initiatives, funding for items such as standing desks or equipment was cost prohibitive. The school had established itself as a leader of health and wellness initiatives within its district, with three years of teachers, staff, and administrators serving as volunteers on their "Strong School Committee." This committee planned, implemented, and improved various wellness initiatives within the school prior to beginning the pedometer program. The pedometer tracking program was named Give Learning Legs (GLL). There were 42 full-time teachers in the school, with 31 self-contained classroom teachers involved in the GLL program. Participation in the program was strictly voluntary, and all participants gave consent by choosing to participate in the program. All procedures followed were in accordance with ethical standards of the responsible committee on human experimentation (institutional and national).

\section{Instrumentation}

Appendix I.

\begin{tabular}{|c|c|c|}
\hline \multicolumn{3}{|c|}{ Movement Activities during the school day (Kindergarten) } \\
\hline Name & Activity Description & Movement Concept \\
\hline \multicolumn{3}{|c|}{ K Math } \\
\hline Sort it Out & $\begin{array}{l}\text { Students can sort by color, shape, and size. Use hoola-hoops outside and give students } \\
\text { objects to sort quickly in teams. }\end{array}$ & Aerobic \\
\hline Fun with 2D Shapes & $\begin{array}{l}\text { Students know the } 6 \text { 2D shapes. Students use their bodies to make shapes. Can be done } \\
\text { individually, partners, or whole group }\end{array}$ & Flexibility \\
\hline Number Magic 0-10 & $\begin{array}{l}\text { Students can count, write, and understand number relationships to } 10 \text {. Students toss } \\
\text { scarves to a partner and practice counting to } 10 .\end{array}$ & Neuromotor \\
\hline Measuring Matters & $\begin{array}{l}\text { Students can measure objects and compare measurements. Students can use their bodies } \\
\text { to measure length of classroom. }\end{array}$ & Flexibility \\
\hline It All Adds Up & $\begin{array}{l}\text { Students can add objects. Show groups of adding students that are completing different } \\
\text { movements. Example: one group, each student is doing a cardio movement, other group is } \\
\text { doing a stretching movement. }\end{array}$ & Flexibility/Aerobic \\
\hline Fun with 3D Shapes & $\begin{array}{l}\text { Students know the } 4 \text { 3D shapes and understand the qualities that make it a 3D shape. } \\
\text { Students stand behind chairs and teacher calls out real life example of 3D shape. Students } \\
\text { complete a movement to show their answer. }\end{array}$ & Neuromotor \\
\hline $\begin{array}{l}\text { Taking Off with } \\
\text { Subtractions }\end{array}$ & $\begin{array}{l}\text { Students can subtract objects. Students complete subtraction problems by walking } \\
\text { backwards on a number line and balancing on the line. }\end{array}$ & Neuromotor \\
\hline What's Your Position? & $\begin{array}{l}\text { Students can use positional words to show location. Students are paired up in twos. One } \\
\text { student is the tree (Stand in tree pose), the other moves their body around the partner by } \\
\text { positional words. After } 5 \text { minutes, they switch. }\end{array}$ & Neuromotor \\
\hline \multicolumn{3}{|c|}{ K Language Arts } \\
\hline We are Special & $\begin{array}{c}\text { Students can tell a story with a matching picture. Students practice telling story to a } \\
\text { partner while walking around classroom, outside track, or walking to another place in } \\
\text { building }\end{array}$ & Aerobic \\
\hline Print has Meaning & $\begin{array}{l}\text { Students understand the basic concepts of a book and how to read a book. During read } \\
\text { around the rug, allow students to lie down on bellies to stretch their spines. }\end{array}$ & Flexibility \\
\hline Growing Readers & $\begin{array}{l}\text { Students can identify characters, setting, and events from a story. Use more than hand } \\
\text { gestures to show character. Person - jump out, Animal - jump on all fours, Object - hunch } \\
\text { down like a rock }\end{array}$ & Neuromotor \\
\hline Growing Writers & $\begin{array}{l}\text { Students can identify punctuation. Use stretching or yoga moves to create the } \\
\text { punctuation. Straight up for exclamation mark, arch your back for question mark, and ball } \\
\text { up your entire body for a period. Hold for } 30 \text { seconds. }\end{array}$ & Flexibility \\
\hline Magical World of Text & $\begin{array}{l}\text { Students can put events in order, and write a story with events in a logical sequence. } \\
\text { 1-Students listen to stories in Cobra position, 2- Students walk, jog, run in place to show } \\
\text { BME. 3- Student squat close to ground for B, hover with hands on knees for M, and stand } \\
\text { tall for E. }\end{array}$ & $\begin{array}{l}\text { 1- Flexibility, 2-Aerobic, } \\
\text { 3-Neoromotor }\end{array}$ \\
\hline Here's What We Think & $\begin{array}{l}\text { Students can make meaning with informational text. Students walk around classroom } \\
\text { with a partner and retells } 3 \text { facts from informational text. }\end{array}$ & Aerobic \\
\hline
\end{tabular}


Each classroom was provided with two Accusplit-AX2710 pedometers and calendars on which to record steps each month. Student and teacher steps were recorded only during academic school hours. Students were active participants in this project, with a rotating student in each classroom taking turns wearing a pedometer and recording both their own steps as well as their teacher's steps. Creating mutual involvement between teachers and students helped to add an element of accountability; the students enjoyed being the "recorder of the day" and encouraged the teachers to continue participating in the program. Before the second year of the intervention, meetings were held with the purpose of adding movement breaks into the curriculum. The changes in curriculum were implemented throughout the second year of the intervention. Throughout the intervention, multiple resources were used to educate and encourage both teachers and students to improve their health behaviors, as research has shown the importance of messaging in pedometer interventions to effect behavior change [34]. Strategies included integrating movement lessons into curriculum; for example, instead of sitting to do spelling, the students would stand or jump when it was their turn to spell. Resources for teachers were distributed by the Wellness Committee with examples for integrating "movement breaks" into learning. An example of how movement was integrated into the school day is provided in Appendix I, which shows different activities used in a kindergarten classroom for the subjects of math and language arts. Similar plans can be created or adapted for different grade levels which contain age appropriate activities for integrating movement and learning during the school day.

\section{Procedure}

Planning for this teacher-driven initiative began in the summer before implementation with highly involved administrative support from an innovative administrative team. Details were presented to teachers at the beginning of the school year with emphasis on education and the purpose behind increasing awareness of physical activity within the school for both students and teachers. A committee of interested teachers, staff members, and administrators was established early in the school year and met on a quarterly basis to discuss and assign intervention responsibilities. Active members served as wellness champions and fulfilled the data collection tasks needed to track and report pedometer outcomes. These school staff members also helped plan activities to increase movement and encourage an active lifestyle. Teachers collaborated on grade-level appropriate ways to incorporate movement into the curriculum and continued participation was encouraged with grade-level competitions. Administrative support and encouragement from principles throughout the year was key to sustaining continued teacher and student participation.

At the beginning of each day, a school-wide administrative announcement was given to remind teachers and students to wear their pedometers. At the end of the school day an additional announcement was made to remind participants to record step totals on the monthly calendars. Step calendars were collected at the end of each month for data analysis and replaced with a blank calendar for the next month. Monthly data analysis included steps averages for both teachers and student classrooms, number of days recorded for the month, and gradewide and school-wide averages for steps and days recorded. Each classroom teacher was given a report with this descriptive data to increase individual teacher awareness of personal, grade, and school-wide steps averages and participation in the program. Results from each month's data summary were posted on a highly visible bulletin board accessible to all, and individual classroom data was placed in teachers' mailboxes. Grade-levels also competed for an end of the year kickball tournament reward. The teacher-led School Wellness Committee worked to keep all adults involved by providing a pedometer and monthly calendar recording tool to any full-time non-classroom teachers or staff interested in participating. Non-classroom teacher/staff data was announced and presented on the bulletin board alongside classroom data, although non-classroom teachers and other staff who participated were not included in this study. Incentives for participation in the pedometer program were provided to all teachers and staff in the month of December with a raffling of health-related prizes such as activity trackers and gift cards. The more day's teachers participated, the more tickets they received for the raffle.

\section{Results}

The goal of this study was first to determine whether or not a significant improvement in the number of steps occurred between the first and second year of the pedometer program, and to determine if the improvement exhibited by teachers is correlated with the improvement exhibited by students. Consequently, analyses used paired samples t-tests and bivariate correlations. Each of the 35 teachers recorded their steps for an average of 8 days each month $(\min =1, \max =24$, mean=8.39). For each day recorded, that teacher's student's steps were also recorded. This procedure was followed for both years of the intervention. Upon the completion of the data collection period, steps were aggregated to their mean for each teacher and their students so that all 35 teachers and students had a mean for each year. Thereafter, some teachers were filtered from the analysis in order to account for inconsistencies such as only participating in a single year of the study or extended periods of absence leading to substitute teachers. After removing these teachers from the analysis, $n=27$ teachers and their collections of students remained for comparison across the two years.

\section{Data Analysis}

Teachers: A paired t-test found a strong and statistically significant increase in the average number of steps taken by teachers between years one and two $(\mathrm{t}(25)=-5.76, \mathrm{p}<0.001$, $\eta 2=0.57)$. On average, teachers took approximately 1339 more steps the second year of the program than they took in the first 
year $(\mathrm{M} 1=5722.8, \mathrm{SD} 1=1119.66, \mathrm{M} 2=7061.35, \mathrm{SD} 2=1484.52)$ (Figure 2).

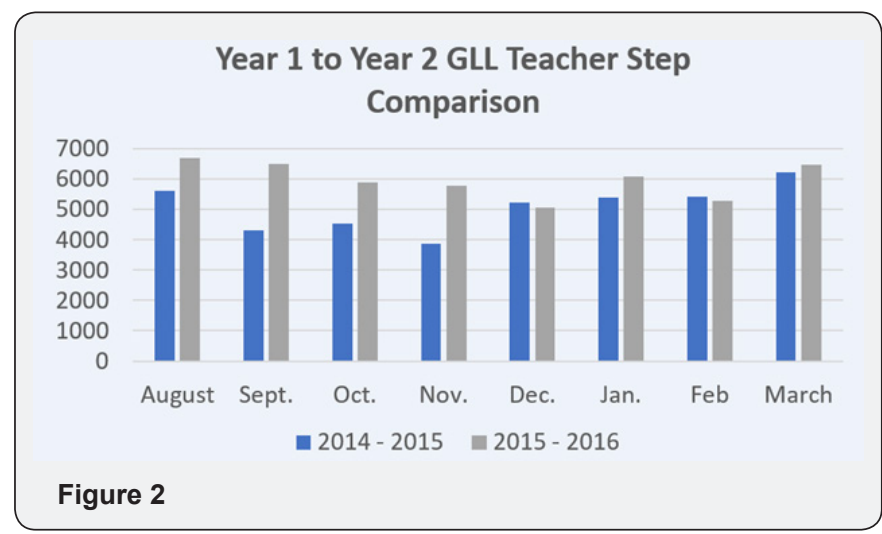

Students: A paired t-test was run on students' scores in years one and two to determine if there was a statistically significant improvement in the number of steps students are taking across the years. We found a strong and statistically significant increase in the number of steps taken by students across years 1 and $2(\mathrm{t}(25)=-9.35, \mathrm{p}<0.001, \eta 2=0.78)$. On average, students took nearly 2000 extra steps (M1=4729.59, SD1=1025.72, M2=6690.78, SD2=1279.51) during the second year of the program. Overall the data revealed that students improved their movement more than the teachers (Figure 3).

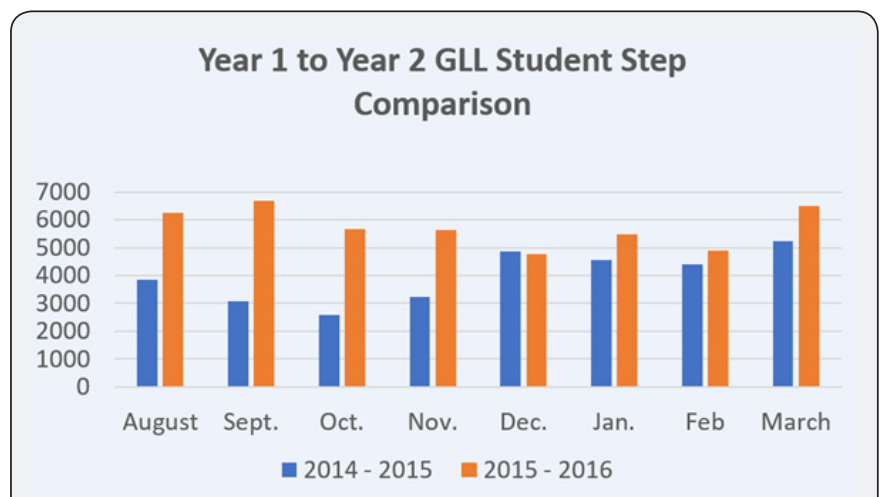

Figure 3

Correlation: Lastly, whether improvements in teachers' performance across the two years of the program were positively correlated with improvements in students' performance across the two years of the program was considered. A bivariate Pearson correlation found a statistically significant and moderate relationship between these two improvements $(r=0.489$, $\mathrm{p}=0.012$ ). Consequently, we can expect that as teachers increase step totals during the intervention, so too will we see students improve.

\section{Limitations}

The biggest limitation in the intervention is that students are not tracked with a unique identifier. We assume every row containing a students' number of steps is a unique student, meaning we lack the ability to account for the low-performing students vs. the high performing students. Being that this project was translational in nature and that teachers "drove the bus," the focus was on keeping day to day activities normal and "doable" for teachers who are burdened with many responsibilities during the school day.

\section{Discussion}

Often, movement interventions implemented in school settings focus strictly on children, and do not consider the teachers. In the creation of this project, there was a concerted effort to increase movement for both students and teachers. As such, the project was approached from a workplace wellness standpoint for teachers (and metaphorically students), which allowed best practices of workplace wellness to be considered. Some of the best practices that have been identified to create a culture that supports and encourages PA in the workplace are: having a wellness committee with representation from all levels of faculty and staff; an organizational commitment to a healthy culture which shows up in the mission and values of the organization; participation incentives, effective and accessible programming options; and measurement and reporting systems in place to monitor progress [35]. The GLL program was created with these best practices in mind, with elements in place to meet each guideline with the end goal of encouraging PA in the workplace. A supportive administrative staff encouraged a dedicated committee to plan and implement movement programming by providing all voluntary participants with pedometers to measure steps and a system of recording and reporting results on an individual and school-wide basis.

The mix of a pedometer program which focused on both students and teachers may help explain the correlation between teacher and student steps. By involving teachers as part of the intervention it may have helped to increase student movement and participation. Another important aspect of the GLL pedometer program was the use of Lau, Wandersman, and Pate's expert perspective on Youth Physical Activity Interventions 36 which was used to understand the GLL program post-intervention. In this article, titled Factors Influencing Implementation of Youth Physical Activity Interventions: An Expert Perspective, twenty-three factors affecting successful youth physical activity intervention implementation (YPAII) were identified using a modified Delphi process [36].

These factors were divided into five categories (organizational characteristics, implementation processes, provider characteristics, program characteristics, and community-level factors). Each factor was further divided (high, moderate, or low) and defined. This clarification of factors into high, medium, or low levels could be helpful to the implementation of youth PA interventions or used retroactively to better understand the reasons why an intervention may (or may not) have been effective, as was done in the case of the GLL program. Although the organizers of the GLL program had no knowledge of these factors, looking retroactively to see which factors were relevant to its' implementation is beneficial in both understanding 


\section{Juniper Online Journal of Public Health}

its' impact to this point as well as the potential for continued positive results in the future. Using the YPAII factors is beneficial in not only planning an intervention, but also helping to identify areas of strength and weakness after implementation. Since each factor is well defined they can be used to understand what improvements need to be made to change a factor from a lower level to a higher one. Six wellness advocates and impactors close to the GLL project were surveyed independently to rate and rank the GLL program. The top four factors reported using the YPAII factors were: a) Leadership Motivation and Engagement,

b) Engaging Program Champion,

c) Adaptability and

d) Reflecting and Evaluating.

Further explanation is included in Table 1. Additionally, the YPAII factors coincide with best practices of workplace wellness, helping to further explain why the program may have been successful in increasing both student and teacher movement in the classroom.

Table 1.

\begin{tabular}{|c|c|c|}
\hline \multicolumn{2}{|c|}{ Top 4 YPAII Factors } \\
\hline Factor & $\begin{array}{c}\text { GLL Explanation } \\
\begin{array}{c}\text { 1. Leadership } \\
\text { Motivation and } \\
\text { Engagement }\end{array}\end{array}$ & $\begin{array}{c}\text { Administrators of the school were especially supportive of the GLL program, especially in establishing policies and } \\
\text { committing to support any activities related to the program. When the committee approached administrators with } \\
\text { suggestions or ideas they often found ways to help- such as allowing reminders to wear pedometers and record steps be } \\
\text { announced over the school intercom system. }\end{array}$ \\
\hline $\begin{array}{c}\text { 2. Engaging } \\
\text { Program Champion }\end{array}$ & $\begin{array}{c}\text { The GLL program was led by a committee which consisted of dedicated movement advocates who worked to provide an } \\
\text { environment where students could learn and thrive in all areas of wellness. }\end{array}$ \\
\hline $\begin{array}{c}\text { 3. Adaptability } \\
\text { 4. Reflecting and } \\
\text { Evaluating }\end{array}$ & $\begin{array}{c}\text { The GLL program was conducted in a manner which could be adapted easily in most school settings. Integrating movement } \\
\text { into the school day using curriculum and movement awareness helps to make the program adaptable elsewhere in a cost- } \\
\text { effective manner. }\end{array}$ \\
\hline $\begin{array}{c}\text { The GLL program utilized daily reminders as well as monthly feedback to reflect on participation and performance on } \\
\text { an individual and school-wide basis. This was done in a manner meant to be systematic and ensure continued program } \\
\text { awareness and success. }\end{array}$ \\
\hline
\end{tabular}

\section{Conclusion}

While both adults and children need to move more during the day, there is little research regarding the correlation of teacher movement in elementary schools to students. Hence, this translational proof of concept study evaluates a program at one Midwestern public elementary school aimed at increasing students and teacher movement throughout the day in a low-cost manner. The pedometer program, led by an internal wellness committee of dedicated volunteer employees and assisted by University Public Health faculty, worked to integrate movement into the school culture as well as the classroom setting. On average, teachers took approximately 1339 more steps and students took nearly 2000 more steps the second year of the program. By the second year of the program, teachers averaged 7,061 steps and students averaged 6,690 steps during the school day. When compared to Tudor-Locke et al. [32] estimate of steps needed to meet daily MVPA guidelines, teachers reached daily guidelines of 7,000-8,000 steps. While students made a larger improvement, they still fell short of the 10,000-11,700 steps associated with 60 minutes of daily MVPA [33]. However, the improvement during the school day remains significant for both groups. The encouragement and low-cost resources provided by the wellness committee helped create a culture of wellness and movement through reminders, programming, incentives, and encouraging teachers to come up with movement ideas which worked best in their own classroom. These activities all helped encourage movement and a way to connect with students while sending a healthy message that increasing daily movement is important. Additionally, the inclusion of both teachers and students could help to increase movement for adults and children while creating accountability for both groups. Perhaps most importantly, the GLL program is one that could be implemented with budgetary concerns in mind, which is important when thinking about an educational setting. While future research is needed to further understand the relationship between student and teacher movement in the classroom, the GLL program provides a low-cost template which could be important to improving health outcomes in large populations in the United States starting with youth. Such programs could be the next step for public health in improving both health and educational outcomes in the classroom.

\section{Acknowledgement}

The Give Learning Some Legs Movement Initiative was funded by grant awards from Action for Healthy Kids $(\$ 4500)$ and Indiana University School of Public Health (\$5000). The majority of grant funding was used for data recording salary, and the purchasing of pedometers/incentives for participation.

\section{Refernces}

1. Xu J, Murphy S, Kochanek K, Elizabeth Arias (2016) Mortality in the United States, 2015. Hyattsville, MD: National Center for Health Statistics

2. (2014) Trust for America's Health, Robert Wood Johnson Foundation. The State of Obesity. 
3. Lou D (2014) Sedentary behaviors and youth: Current trends and the impact on health. Active Living Research.

4. Committee PAGA (2008) Physical Activity Guidelines for Americans. Department of Health and Human Services, Washington, DC, USA.

5. Center for Disease Control. Childhood Obesity Facts.

6. Indiana State Department of Health (2010) Indiana Healthy Weight Initiative, Indiana's Comprehensive Physical Activity and Nutrition Plan 2010-2020. Indiana State Department of Health.

7. (2013) Center for Disease Control. Youth Risk Behavior Survey- Trends in the Prevelance of Physical Activity and Sedetary Behaviors National YRBS 1991-2013.

8. Center for Disease Control (2013) Youth Risk Behavior Survey.

9. Center for Disease Control (2016) Healthy Schools, Physical Activity.

10. Mullender Wijnsma MJ, Hartman E, De GreeffJW, Simone Doolaard, Roel J Bosker, et al. (2016) Physically Active Math and Language Lessons Improve Academic Achievement: A Cluster Randomized Controlled Trial. Pediatrics 137(3): 2015-2743.

11. Kibbe DL, Hackett J, Hurley M, Mc Farland A, Schubert KG et al. (2011) Ten Years of TAKE 10 (R): Integrating physical activity with academic concepts in elementary school classrooms. Prev Med 52(Suppl 1): 4350 .

12. Mullender Wijnsma MJ, Hartman E, de Greeff JW, Simone Doolaard, Roel J Bosker, et al. (2015) Moderate to vigorous physically active academic lessons and academic engagement in children with and without a social disadvantage: a within subject experimental design. BMC Public Health 15: 404.

13. Mahar MT (2011) Impact of short bouts of physical activity on attention to task in elementary school children. Prev Med 52(Suppl 1): 60-64.

14. Carlson JA, Engelberg JK, Cain KL, Conway TL, Mignano AM, et al. (2015) Implementing classroom physical activity breaks: Associations with student physical activity and classroom behavior. Prev Med 81: 67-72.

15. Kall LB, Nilsson M, Linden T (2014) The impact of a physical activity intervention program on academic achievement in a Swedish elementary school setting. J Sch Health 84(8): 473-480.

16. Abbott RA, Straker LM, Mathiassen SE (2013) Patterning of children's sedentary time at and away from school. Obesity (Silver Spring) 21(1): 131-133.

17. Oppezzo M, Schwartz DL (2014) Give your ideas some legs: The positive effect of walking on creative thinking. Journal of experimental psychology learning, memory, and cognition 40(4): 1142-52

18. Shuval K, Finley CE, Barlow CE, Gabriel KP, Leonard D, et al. (2014) Sedentary behavior, cardiorespiratory fitness, physical activity, and cardiometabolic risk in men: the cooper center longitudinal study. Mayo Clin Proc 89(8): 1052-1062.

19. Owen N, Sparling PB, Healy GN, David W Dunstan and Charles E Matthews (2010) Sedentary behavior: emerging evidence for a new health risk. Mayo Clin Proc 85(12): 1138-1141.
20. (2018) Physical Activity Guidelines Advisory Committee. Physical Activity Guidelines Advisory Committee Scientific Report.

21. Nike (2013) Designed to Move - A Physical Activity Action Agenda. American College of Sports Medicine. International Council of Sports Science and Physical Education.

22. (2016) National Physical Activity Plan Alliance. National Physical Activity Plan.

23. Kohl H, Cook H (2013) Educating the Student Body: Taking Physical Activity and Physical Education to School. Institute of Medicine, Food and Nutrition Board, Committee on Physical Activity and Physical Education in the School Environment, Washington (DC): National Academies Press, USA.

24. Koepp GA, Snedden BJ, Flynn L (2012) Feasibility analysis of standing desks for sixth graders. ICAN: Infant, Child \& Adolescent Nutrition 4(2): 89-92.

25. Erwin HE, Fedewa A, Ahn S (2016) Elementary Students' Physical Activity Levels and Behavior When Using Stability Balls. Am J Occup Ther 70(2): 700220010p1-700220010.

26. Minges KE, Chao AM, Irwin ML (2016) Classroom Standing Desks and Sedentary Behavior: A Systematic Review. Pediatrics 137(2): e20153087.

27. Center for Disease Control and Prevention (2013) Comprehensive School Physical Activity Programs: A Guide for Schools. US Department of Health and Human Services.

28. Erwin HE, Abel MG, Beighle A (2011) Promoting children's health through physically active math classes: a pilot study. Health Promot Pract 12(2): 244-251.

29. Erwin HE, Beighle A, Morgan CF (2011) Effect of a low-cost, teacherdirected classroom intervention on elementary students' physical activity. J Sch Health 81(8): 455-461.

30. Lanningham Foster L, Foster RC, McCrady SK (2008) Changing the school environment to increase physical activity in children. Obesity (Silver Spring) (8): 1849-1853.

31. Buettner D (2015) The Blue Zones Solution. National Geographic, Washington, DC, USA.

32. Tudor Locke C, Craig CL, Brown WJ (2011) How many steps/day are enough? for adults. International Journal of Behavioral Nutrition and Physical Activity 8(1): 79.

33. Tudor Locke C, Craig CL, Beets MW (2011) How many steps/day are enough? For children and adolescents. Int J Behav Nutr Phys Act 28(8): 78.

34. Lubans DR, Plotnikoff RC, Miller A (2014) Using Pedometers for Measuring and Increasing Physical Activity in Children and Adolescents. American Journal of Lifestyle Medicine 9(6).

35. Pronk N (2014) Best practice design principles of worksite health and wellness programs. ACSM's Health \& Fitness Journal 18(1): 42-46.

36. Lau E, Wandersman A, Pate R (2016) Factors Influencing Implementation of Youth Physical Activity Interventions: An Expert Perspective. TJACSM 1(7): 1002-1011. 
This work is licensed under Creative Commons Attribution 4.0 License DOI:10.19080/JOJPH.2018.03.555612

\section{Your next submission with Juniper Publishers will reach you the below assets}

- Quality Editorial service

- Swift Peer Review

- Reprints availability

- E-prints Service

- Manuscript Podcast for convenient understanding

- Global attainment for your research

- Manuscript accessibility in different formats ( Pdf, E-pub, Full Text, Audio)

- Unceasing customer service

Track the below URL for one-step submission https://juniperpublishers.com/online-submission.php 